\title{
Study of Thermophysical Properties of Polymer Materials Enhanced by Nanosized Particles
}

\author{
O. V. Tushavina ${ }^{1}$, G. I. Kriven ${ }^{1}$, Thant Zin Hein ${ }^{2}$, \\ ${ }^{1}$ Moscow Aviation Institute (National Research University), \\ Moscow, Volokolamskoe shosse, 4, 125993, \\ Russia \\ ${ }^{2}$ Defense Services Technological Academy (DSTA), \\ Mandalay Lashio Highway, Pyin Oo Lwin, Mandalay Division, \\ Myanmar
}

Received: March 10, 2021. Revised: August 15, 2021. Accepted: September 12, 2021. Published: September 14, 2021.

\begin{abstract}
In this work, the object of study is an epoxy nanocomposite based on $\mathrm{TiO}_{2}$ nanoparticles and epoxy resin, and the subject is the preparation and physical and mechanical properties of $\mathrm{TiO}_{2} /$ epoxy nanocomposites. The characteristics of the properties and methods of synthesis of the initial components for the synthesis of epoxy nanocomposites - epoxy resins and nanoparticles of titanium dioxide are given, and data on epoxy nanocomposites based on nanoparticles of titanium dioxide are presented. It was found that the addition of $\mathrm{TiO}_{2}$ to the epoxy matrix reduces the coefficient of friction and significantly increases the wear resistance of such nanocomposites.
\end{abstract}

Keywords-Composites, polymers, titanium dioxide, adsorption.

\section{INTRODUCTION}

$\mathrm{I}$ $\mathrm{N}$ order for the polymer matrix to withstand high mechanical loads, it is reinforced with fillers. Nanoparticles are more effective fillers than coarse particles. Due to the small size and high surface energy of nanoparticles, the improvement of the properties of nanocomposites is achieved at a much lower filler concentration [1]-[9].

Modern composites have not only a wide range of physical and mechanical properties, but are also capable of directionally changing them, for example, increasing fracture toughness, regulating rigidity, strength, and other properties. These possibilities are expanded when fibers of different nature and geometry are used in composites, i.e., when creating hybrid composites. In addition, these materials are characterized by the appearance of a synergistic effect (coordinated joint action of several factors in one direction).

The properties of the interface or interfacial zone, first of all, the adhesive interaction between the fiber and the matrix, determine the level of properties of composites and their retention during operation. Local stresses in the composite reach their maximum values just near or directly at the interface, where material destruction usually begins. The interface must have certain properties to ensure efficient transfer of the mechanical load from the matrix to the fiber. The adhesion bond at the interface should not be destroyed under the action of thermal and shrinkage stresses arising from the difference in the temperature coefficients of linear expansion of the matrix and fiber or as a result of chemical shrinkage of the binder during its curing.

When creating nanocomposites, the key tasks are the development of efficient, reliable, and affordable production technologies for mass production, which make it possible to obtain materials with stable characteristics. The hand lay technique, also called wet lay, is the simplest and most widely used process for producing flat reinforced composites. The process consists of laying layers of a polymer in successive layering using an epoxy matrix. Wet-laying is a molding process that combines layers of reinforced carbon fiber with epoxy to create a high-quality laminate. Before starting the installation process, you must prepare the appropriate form. This preparation consists of cleaning the table and applying a release agent to the surface. The manual laying process can be divided into four main steps: mold preparation, epoxy coating, laying and curing. Form preparation is one of the most important steps in the installation process. This process requires dry reinforcement layers and the application of a wet epoxy matrix. They are connected together - reinforcing material, impregnated with a matrix - epoxy resin.

Titanium dioxide is one of the promising materials as a 
nanofiller due to its optical, thermal, photocatalytic and electrophysical properties. The application potential of nanodispersed $\mathrm{TiO}_{2}$ is very high: titanium dioxide and materials based on it can be used as an additive in plastics, an ultraviolet light blocker, an energy converter in solar batteries, an agent for photocatalytic degradation of bacteria and photochemical degradation of toxic chemicals, for wastewater treatment. Due to their chemical inertness, low toxicity, photocatalytic activity, high refractive index and other beneficial properties, titanium dioxide $\left(\mathrm{TiO}_{2}\right)$ nanoparticles have attracted the attention of many researchers and are used in the food, paint and varnish industry, etc. Previous studies have shown that the introduction of $\mathrm{TiO}_{2}$ nanoparticles improves some properties of epoxy resin. But the process of interaction and the mechanism of hardening of epoxy resin are not fully understood [44]-[52]. There are few works on epoxy nanocomposites with $\mathrm{TiO}_{2}$ nanoparticles; therefore, it is relevant to obtain new examples of such nanocomposites and study their physical and mechanical properties, since due to the presence of $\mathrm{TiO}_{2}$, it is possible to use such nanocomposites in biomedicine, as bactericidal and photocatalytic surfaces. The aim of this work is to create an epoxy nanocomposite based on $\mathrm{TiO}_{2}$ nanoparticles and to study its physical and mechanical properties depending on the concentration of nanoparticles.

The matrix can be a thermosetting polymer - epoxy resin, which has already found many applications: from structural composites to adhesives and surface coatings. Epoxy resins already have a number of unique qualities among polymers: no shrinkage during curing, high adhesion to various substrates, good dielectric and other valuable properties [36]-[44]. Nanocomposites using thermoplastic polymers are well known and studied to improve mechanical, electrical, thermal and insulating properties [45]-[74]. However, nanocomposites using thermosetting polymers have not been studied as widely, especially using $\mathrm{TiO}_{2}$.

$\mathrm{TiO}_{2}$ nanoparticles embedded in a polymer matrix are attracting more and more interest due to the unique mechanical, optical, electrical and magnetic properties exhibited by nanocomposites [10]-[17]. There are two ways to obtain nanocomposite materials. The first in situ method is a one-step method, which consists in the fact that the synthesis of nanoparticles and a polymer matrix occurs simultaneously, resulting in the formation of a nanocomposite. The disadvantage of this method is that the products of the synthesis of nanoparticles remain in the nanocomposite. Another way to obtain nanocomposites is a multistage ex situ method. In the multistage method, each of the stages of nanocomposite formation is separated into a separate process. It is necessary to synthesize stable nanoparticles, isolate them, then disperse them in a polymer matrix or in an oligomer, followed by polymerization [18]-[27]. The difficulty in creating nanoclusters by the ex situ method lies in the dispersion of nanoparticles in the bulk, which requires additional equipment (high-performance mills, ultrasound, etc.), the use of surfactants, etc. [28]-[35]. In a number of works, titanium-containing coatings were obtained by photopolymerization of nanocomposites based on epoxy resin [36]-[40]. The initial nanocomposite was obtained in two ways: by dispersing preformed $\mathrm{TiO}_{2}$ nanoparticles and by in situ using a sol-gel process. According to the results of the analysis of transmission electron microscopy (TEM), it was shown that using the in situ method it is possible to achieve a more uniform distribution of nanoparticles in the matrix, without the formation of agglomerations.

The one-stage method of forming nanocomposites is more technological, does not require additional equipment and additional energy and labor costs for synthesis, isolation of nanoparticles, their stabilization and combination with a polymer matrix, as required in a multistage method.

However, nanocomposites using thermosetting polymers have not been studied so widely, especially with the use of $\mathrm{TiO}_{2}$, and there is a need for more experimental and theoretical studies of nanocomposites filled with $\mathrm{TiO}_{2}$ nanoparticles.

\section{STUDY OF THE PROPERTIES OF NANOCOMPOSITES}

Nanoparticles, even with a very low volumetric content (less than $1 \%$ ), are contained in such a fragment in a very large amount, and it is impossible to model their effect at this scale level. For example, a cubic fragment of a $1 \mu \mathrm{m}$ matrix contains more than thousand nanoparticles for a given volumetric content. Therefore, in particular, the nano-modified binder is white, while the usual binder is yellow. To model such materials, it is necessary to resort to multiscale approaches and to carry out a consistent determination of effective properties at various scale levels. This task is greatly simplified if the properties of the nanomodified matrix are known from experiments. In particular, it is known that its Young's modulus is $2.5 \mathrm{GPa}$. The missing characteristic is Poisson's ratio, which can be approximately taken unchanged, or estimated on the basis of analytical calculations using the found value of the "effective" volumetric content of the filler, which was done. Further, it suffices to numerically solve the averaging problem on a representative fragment containing only nanoparticles.

Based on the results of experimental studies, the effective characteristics of a monolayer made of a composite material based on both conventional and nanomodified matrices were determined, and a solution to the corresponding inverse problem was obtained. It was found that the addition of nanoparticles within the recommended standard range of $10 \%$ leads to a slight increase in the longitudinal elastic modulus and shear modulus of the monolayer. In this case, there is an almost twofold decrease in the elastic modulus in the transverse direction and a decrease to zero Poisson's ratio. The reliability of the developed numerical models is confirmed by a good correlation between the results of both numerical and analytical solutions and the obtained experimental data on the study of the thermomechanical characteristics of nanomodified materials. 
The properties of the obtained nanocomposites depend on many factors: size, shape, concentration of nanoparticles, etc. The unique properties of the nanocomposite can also be achieved by good dispersion of nanoparticles in the surrounding epoxy matrix. In the article [3], it was found that $\mathrm{TiO}_{2}$ nanoparticles can be homogeneously dispersed in epoxy resins using ultrasound, which improved mechanical properties and scratch resistance compared to traditional epoxy resins with microparticles. It was shown in [4] that for the best distribution of nanoparticles in the matrix, the ultrasonic dispersion time should be 2 minutes. Increasing the dispersion time further increases the temperature and viscosity of the resin. For even distribution, the loading percentage of nanoparticles should be $1 \%$. It is believed that a larger particle size improves dispersion, since smaller particles have a greater Van der Waals force between themselves. This is proved by the TEM results in Figure 1.

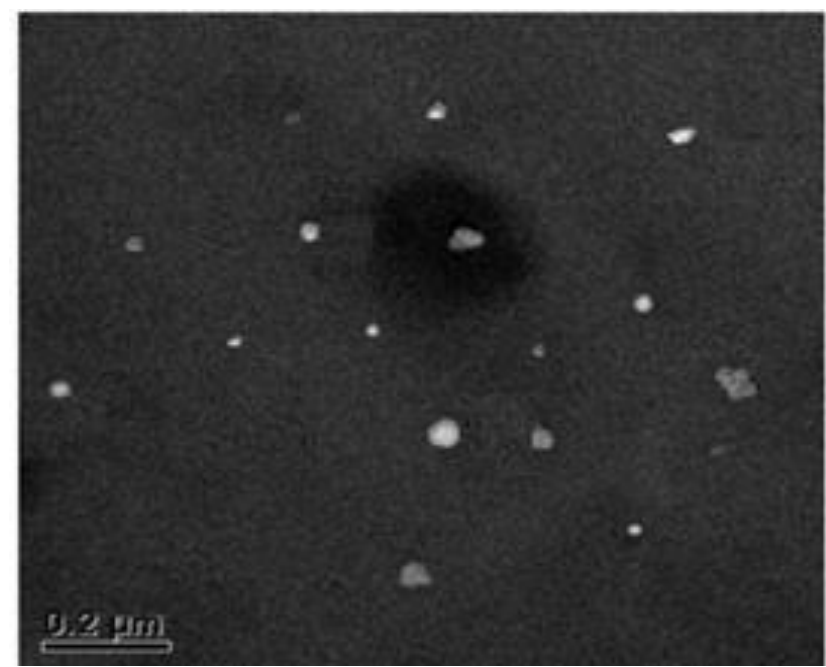

Fig. $1 \mathrm{Tem}$ of $\mathrm{TiO}_{2}$-epoxy nanocomposite $\left(5 \mathrm{~nm}, 1 \% \mathrm{TiO}_{2}\right)$.

$\mathrm{TiO}_{2}$ nanofillers have a large surface area, which makes them chemically very reactive and helps them to better bond with the matrix, therefore nanosized particles have advantages over others. This is confirmed in Figure 2, where it can be seen that composites with nanosized $\mathrm{TiO}_{2}(\sim 50 \mathrm{~nm})$ are superior in mechanical properties to microcomposites $(\sim 50 \mu \mathrm{m})$.

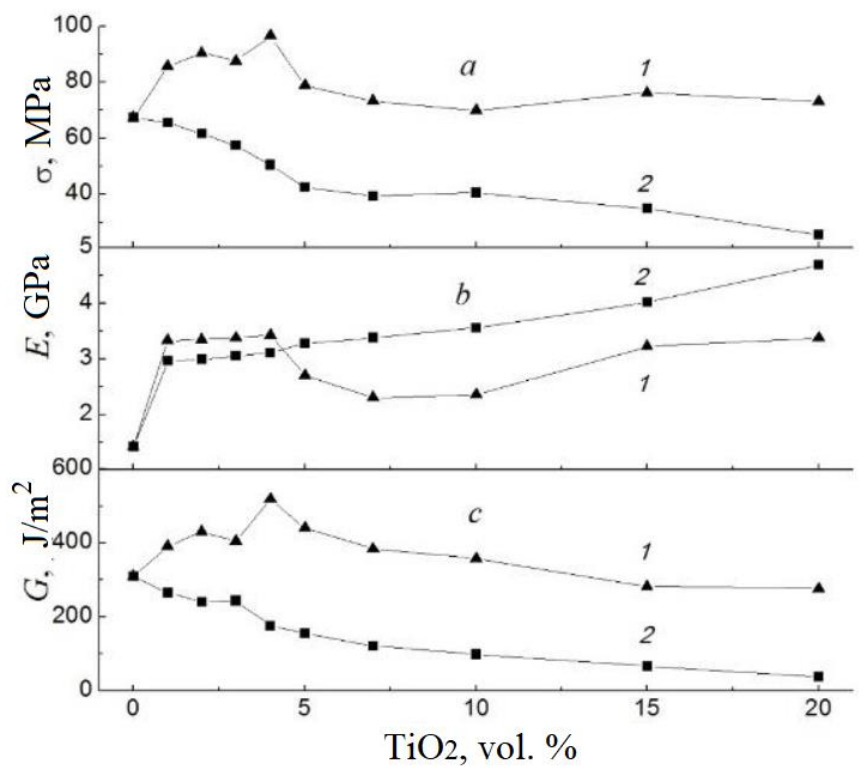

Fig. 2 Dependence of the mechanical properties of the composite on the concentration of nano- (1) and microparticles (2) $\mathrm{TiO}_{2}$ : a strength, $\mathrm{b}$ - modulus, $\mathrm{c}$ - fracture energy.

As can be seen from Figure 2, all mechanical characteristics increase until the concentration of titanium dioxide nanoparticles in the composite reaches $4 \%$. The subsequent fall is probably due to the enlargement of particles due to their agglomeration. Figure 3 shows that the tensile strength is maximum at $10 \%$ loading of nanoparticles, and the fracture strain and impact strength at 5\%, which is $26 \%, 18 \%$ and $54 \%$, respectively, more compared to pure epoxy resin. There is also evidence that improved mechanical properties are observed even at a very low content of $\mathrm{TiO}_{2}$ nanoparticles $\sim 1 \%$.

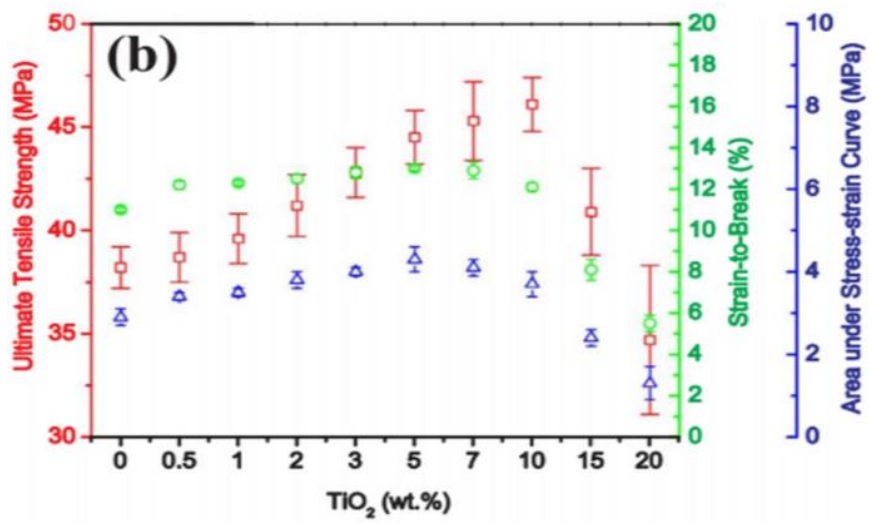

Fig. 3 Change in tensile strength (red graph), fracture strain\% (green graph) and impact strength (blue graph) depending on the content of $\mathrm{TiO}_{2}$ nanoparticles.

To understand the bonding mechanism, Fourier transform infrared spectroscopy was performed. IR spectra show a slight shift of the peak towards a lower wavelength $\left(3418 \mathrm{~cm}^{-1}\right)$, which is associated with the stretching of the $\mathrm{OH}$ hydroxyl group on the surface of nanoparticles and epoxy resins, which tells us about their hydrogen bonding. Another article also talks about the hydrogen bond between $\mathrm{TiO}_{2}$ nanoparticles and 
epoxy resin. The strong absorption band at $610-630 \mathrm{~cm}^{-1}$ corresponds to the Ti-O-Ti bonds, which prove that $\mathrm{TiO}_{2}$ has been successfully prepared and incorporated into the epoxy matrix.

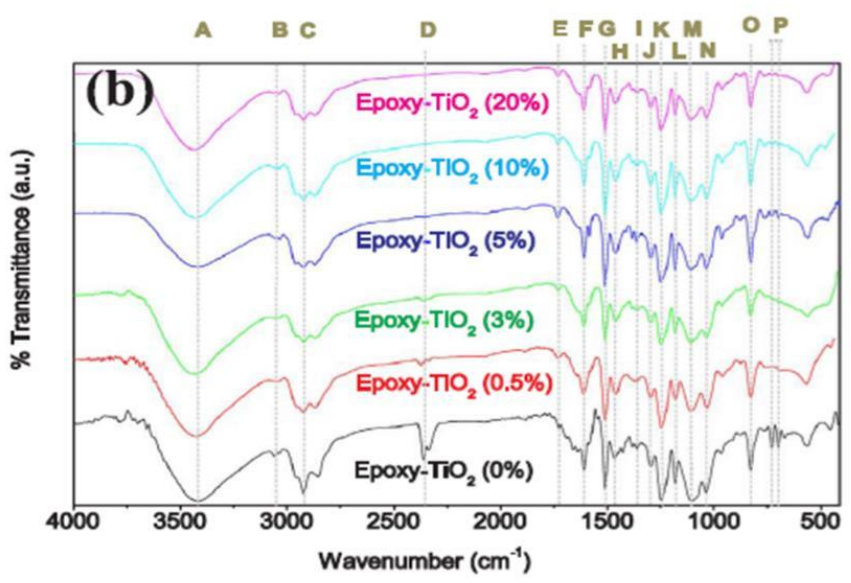

Fig. 4 ir spectra of epoxy nanoclusters with $\mathrm{TiO}_{2}$ nanoparticles.

It was found that the addition of $\mathrm{TiO}_{2}$ to the epoxy matrix reduces the coefficient of friction and significantly increases the wear resistance of such nanocomposites. The decomposition characteristics of a sample of a polymer paste reinforced with epoxy resin and $\mathrm{TiO}_{2}$ were investigated. Sample exposed into phosphoric acid for 90 days $(\mathrm{pH}=3,0$ 4,0 ). The results showed that the sample reinforced with epoxy resin and $\mathrm{TiO}_{2}$ nanoparticles had low water absorption rates and was more resistant to penetration of water, acid, and other solutions. The degradation depth is $8-10 \%$ less compared to the control sample, which can be seen in Figure 5.

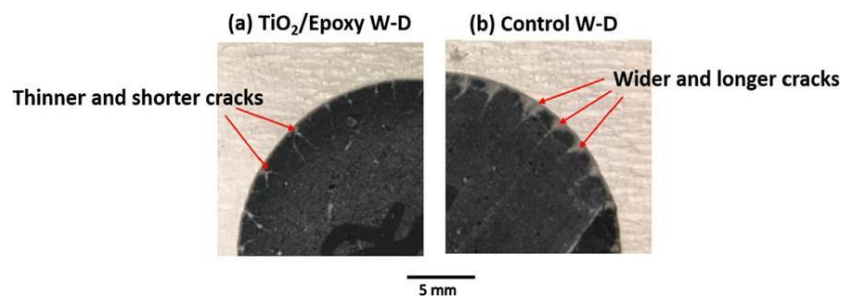

Fig. 5 Enlarged portions of the samples after 90 days of exposure to the phosphoric acid cycle and the environment, (a) a $\mathrm{TiO}_{2} /$ epoxy sample and (B) a control sample.

Epoxy nanocomposites can be used as refractive index tunable films. It has been investigated and shown that the refractive index of hybrid films can increase linearly with a percentage of $\mathrm{TiO}_{2}$ and reach 1,731 at a titanium dioxide content of $20 \%$ (Figure 6).

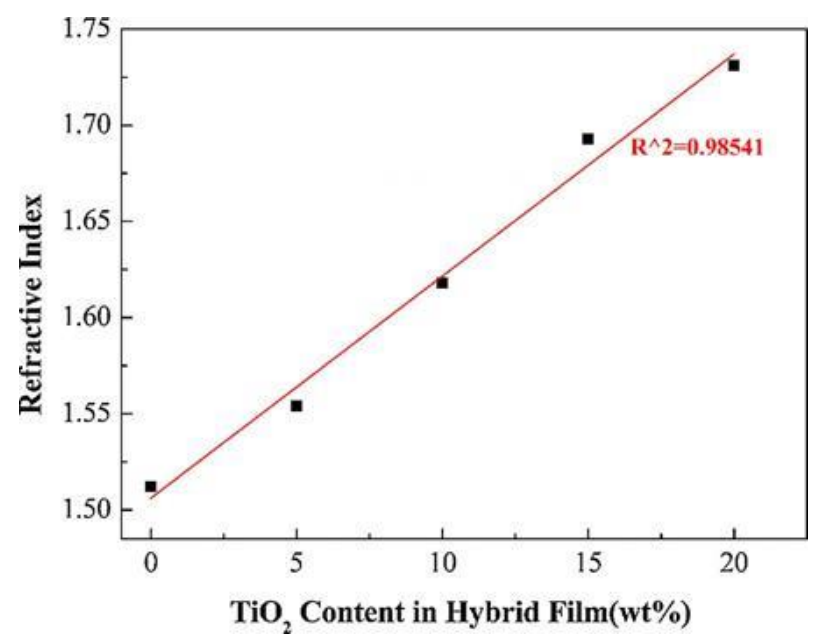

Fig. 6 Influence of $\mathrm{TiO}_{2}$ content on the refractive index of epoxy/ $\mathrm{TiO}_{2}$ hybrid films.

\section{CONCLUSION}

Thus, the resulting epoxy nanocomposites with the advantages of good thermal, physical, mechanical, optical and other properties have great prospects for application in modern optical, medical, and structural purposes. It was found that the addition of $\mathrm{TiO}_{2}$ to the epoxy matrix reduces the coefficient of friction and significantly increases the wear resistance of such nanocomposites.

It was shown, that all mechanical characteristics increase until the concentration of titanium dioxide nanoparticles in the composite reaches $4 \%$. The subsequent fall is probably due to the enlargement of particles due to their agglomeration.

IR spectra show a slight shift of the peak towards a lower wavelength $\left(3418 \mathrm{~cm}^{-1}\right)$, which is associated with the stretching of the $\mathrm{OH}$ hydroxyl group on the surface of nanoparticles and epoxy resins, which tells us about their hydrogen bonding.

Summarizing, the application of ceramics nanoparticles as fillers of polymer matrix allows for obtaining of composites with improved mechanical characteristics. Such composites can find their application as functional and construction materials.

This study was funded by RFBR, project number 20-0800880 .

\section{REFERENCES}

[1] L. N. Rabinskiy, S. A. Sitnikov, "Development of technologies for obtaining composite material based on silicone binder for its further use in space electric rocket engines," Periodico Tche Quimica, 15(Special Issue 1), pp. 390-395, 2018.

[2] A. A. Orekhov, Y. A. Utkin, P. F. Pronina, "Determination of deformation in mesh composite structure under the action of compressive loads," Periodico Tche Quimica, 17(35), pp. 599-608, 2020.

[3] O. A. Butusova, "Surface Modification of Titanium Dioxide Microparticles Under Ultrasonic Treatment," 
International Journal of Pharmaceutical Research, vol. 12, i. 4, pp. 2292-2296, 2020.

[4] O. A. Butusova. "Adsorption Behaviour of Ethylhydroxyethyl Cellulose on the Surface of Microparticles of Titanium and Ferrous Oxides," International Journal of Pharmaceutical Research, vol. 12, Supplementary Issue 2, pp. 1156-1159, 2020.

[5] I. P. Lifanov, A. N. Astapov, V. S. Terentieva, "Deposition of heat-resistant coatings based on the $\mathrm{ZrSi} 2-$ MoSi2-ZrB2 system for protection of non-metallic composite materials in high-speed high-enthalpy gas flows," Journal of Physics: Conference Series, vol. 1713, no. 1, pp. 012025, 2020.

[6] I. O. Lifanov, A. A. Yurishcheva, A. N. Astapov, "Hightemperature protective coatings on carbon composites," Russian Engineering Research, vol. 39, no. 9, pp. $804-$ 808, 2019.

[7] A. N. Astapov, I. P. Lifanov, M. V. Prokofiev, "Hightemperature interaction in the $\mathrm{ZrSi} 2-\mathrm{ZrSiO} 4$ system and its mechanism," Russian Metallurgy (Metally), no. 6, pp. $640-646,2019$.

[8] O. A. Butusova, "Stabilization of Carbon Microparticles by High-Molecular Surfactants," International Journal of Pharmaceutical Research, vol. 12, Supplementary Issue 2, pp. 1147-1151, 2020.

[9] O. A. Butusova, "Vinyl Ether Copolymers as Stabilizers of Carbon Black Suspensions," International Journal of Pharmaceutical Research, vol. 12, Supplementary Issue 2, pp. 1152-1155, 2020.

[10]A. N. Tarasova, "Vibration-based Method for Mechanochemical Coating Metallic Surfaces," International Journal of Pharmaceutical Research, vol. 12, Supplementary Issue 2, pp. 1160-1168, 2020.

[11] O. A. Pashkov, "Influence of Polymer Coatings on the Mechanical Properties of Steel Samples in Tensile and Bending Tests," Turkish Journal of Computer and Mathematics Education (TURCOMAT), vol. 12, no. 5, pp. 542-548, 2021.

[12] O. A. Pashkov, "Investigation of the Effect of Steel Plate Size and Elevated Temperature on Critical Load in Stability Tests," Turkish Journal of Computer and Mathematics Education (TURCOMAT), vol. 12, no. 10, pp. 1657-1663, 2021.

[13] Y. Sun, O. V. Egorova, E. L. Kuznetsova, "Identification of the front angle of a plane acoustic oblique pressure wave on convex surfaces with the use of analytical solution," Journal of the Balkan Tribological Association, 27(2), pp. 189-197, 2021.

[14] O. A. Pashkov, "Theoretical calculation of the thickness of interphase zones in the Al-Al2O3 composite," Turkish Journal of Computer and Mathematics Education (TURCOMAT), vol. 12, no. 10, pp. 1672-1677, 2021.

[15] O. A. Pashkov, "Experimental and Theoretical Study of Mechanical Properties of Matrix Composite Materials," Turkish Journal of Computer and Mathematics Education (TURCOMAT), vol. 12, no. 10, pp. 1678-1684, 2021.

[16]A. N. Tarasova, "Effect of Reagent Concentrations on Equilibria in Water-Soluble Complexes," International
Journal of Pharmaceutical Research, vol. 12, Supplementary Issue 2, pp. 1169-1172, 2020.

[17]N. A. Kucheva, V. Kohlert, "Mathematical modeling methods for estimation the thermophysical properties of heat-protective composite materials," Turkish Journal of Computer and Mathematics Education (TURCOMAT), vol. 12, no. 10, pp. 1606-1612, 2021.

[18]A. N. Tarasova, "Effect of Vibration on Physical Properties of Polymeric Latexes," International Journal of Pharmaceutical Research, vol. 12, Supplementary Issue 2, pp. 1173-1180, 2020.

[19] A. V. Babaytsev, L. N. Rabinskiy, K. T. Aung, "Investigation of the contact zone of a cylindrical shell located between two parallel rigid plates with a gap," INCAS Bulletin, 12(Special Issue), pp. 43-52, 2020.

[20] V. G. Dmitriev, O. V. Egorova, E. I. Starovoitov, "Particularities of mathematical modeling of deformation processes for arched and panel designs of composites with large displacements and rotation angles," INCAS Bulletin, 12(Special Issue), pp. 53-66, 2020.

[21]O. V. Egorova, E. I. Starovoitov, "Non-stationary diffraction problem of a plane oblique pressure wave on the shell in the form of a hyperbolic cylinder taking into account the dissipation effect," INCAS Bulletin, 12(Special Issue), pp. 67-77, 2020.

[22]N. A. Kucheva, "Investigation of the mechanical properties of heat-protective highly porous composite materials using the effective medium model," Turkish Journal of Computer and Mathematics Education (TURCOMAT), vol. 12, no. 10, pp. 1613-1621, 2021.

[23] N. A. Kucheva, V. Kohlert, "Analytical solution of the problem of thermoelasticity for a plate heated by a source with a constant heat supply on one surface," Turkish Journal of Computer and Mathematics Education (TURCOMAT), vol. 12, no. 10, pp. 1622-1633, 2021.

[24] S. Vakhneev, E. Starovoitov, "Damping of circular composite viscoelastic plate vibration under neutron irradiation," Journal of Applied Engineering Science, 18(4), pp. 699-704, 2020.

[25] V. A. Pogodin, L. N. Rabinskii, S. A. Sitnikov, "3D Printing of Components for the Gas-Discharge Chamber of Electric Rocket Engines," Russian Engineering Research, vol. 39, no. 9, pp. 797-799, 2019.

[26] O. A. Butusova, "Design and Properties of Magnetically Controlled Sorbents," Turkish Journal of Computer and Mathematics Education (TURCOMAT), vol. 12, no. 5, pp. 515-519, 2021.

[27] O. A. Butusova, "Application of Magnetically Controlled Sorbents for Detoxication," Turkish Journal of Computer and Mathematics Education (TURCOMAT), vol. 12, no. 5, pp. 520-524, 2021.

[28]M. O. Kaptakov, "Effect of Thin Polymer Layers on Mechanical Properties of Metal Surfaces," Turkish Journal of Computer and Mathematics Education (TURCOMAT), vol. 12, no. 5, pp. 525-529, 2021.

[29] B. A. Garibyan, "Determination of the Elastic Modulus of the Coating Using a Spherical Indenter," Turkish Journal 
of Computer and Mathematics Education (TURCOMAT), vol. 12, no. 10, pp. 1594-1600, 2021.

[30] M. O. Kaptakov, "Modelling of Mechanical Properties of Metal Plates with Polymer Coatings," Turkish Journal of Computer and Mathematics Education (TURCOMAT), vol. 12, no. 5, pp. 530-534, 2021.

[31]B. A. Garibyan, "Theoretical Estimations of Influence of Polymer Coatings on the Elastic Modulus and Ultimate Strength of Steel Samples," Turkish Journal of Computer and Mathematics Education (TURCOMAT), vol. 12, no. 10, pp. 1651-1656, 2021.

[32] M. O. Kaptakov, "Investigation of Effective Mechanical Characteristics of Nanomodified Carbon-Epoxide Composite by Numerical and Analytical Methods," Turkish Journal of Computer and Mathematics Education (TURCOMAT), vol. 12, no. 5, pp. 535-541, 2021.

[33] M. O. Kaptakov, "Obtaining of Carbon Fibers Based Composite Materials and Study of Their Mechanical Properties," Turkish Journal of Computer and Mathematics Education (TURCOMAT), vol. 12, no. 10, pp. 1601-1605, 2021.

[34] Y. K. Kyaw, E. L. Kuznetsova, A. V. Makarenko "Complex mathematical modelling of mechatronic modules of promising mobile objects," INCAS Bulletin, 12(Special Issue), pp. 91-98, 2020.

[35] L. E. Kuznetsova, V. G. Fedotenkov, "Dynamics of a spherical enclosure in a liquid during ultrasonic cavitation," Journal of Applied Engineering Science, 18(4), pp. $681-686,2020$.

[36] A. V. Makarenko, E. L. Kuznetsova, "Energy-Efficient Actuator for the Control System of Promising Vehicles," Russian Engineering Research, 39(9), pp. 776-779, 2019.

[37]E. L. Kuznetsova, A. V. Makarenko, "Mathematic simulation of energy-efficient power supply sources for mechatronic modules of promising mobile objects," Periodico Tche Quimica, 15(Special Issue 1), pp. 330338, 2018.

[38] Y. Li, A. M. Arutiunian, E. L. Kuznetsova, G. V. Fedotenkov, "Method for solving plane unsteady contact problems for rigid stamp and elastic half-space with a cavity of arbitrary geometry and location," INCAS Bulletin, 12(Special Issue), pp. 99-113, 2020.

[39] E. L. Kuznetsova, G. V. Fedotenkov, E. I. Starovoitov, "Methods of diagnostic of pipe mechanical damage using functional analysis, neural networks and method of finite elements," INCAS Bulletin, 12(Special Issue), pp. 79-90, 2020.

[40] Y. K. Kyaw, P. F. Pronina, P. O. Polyakov, "Mathematical modelling of the effect of heat fluxes from external sources on the surface of spacecraft," Journal of Applied Engineering Science, 18(4), pp. 732-736, 2020.

[41] V. F. Formalev, S. A. Kolesnik, B. A. Garibyan, "Mathematical modeling of heat transfer in anisotropic plate with internal sinks," AIP Conference Proceedings, 2181, 020003, 2019.

[42] Yu. V. Ioni, A. Ethiraj, "New Tailor-Made Polymer Stabilizers for Aqueous Dispersions of Hydrophobic Carbon Nanoparticles," International Journal of
Pharmaceutical Research, vol. 12, i. 4, pp. 3443-3446, 2020.

[43] Yu. V. Ioni, "Nanoparticles of noble metals on the surface of graphene flakes," Periodico Tche Quimica, vol. 17, no. 36, pp. 1199-1211, 2020.

[44] M. O. Kaptakov, "Catalytic Desulfuration of Oil Products under Ultrasonic Treatment," International Journal of Pharmaceutical Research, vol. 12, Supplementary Issue 2, pp. 1838-1843, 2020.

[45]B. A. Garibyan, "Enhancement of Mechanical Properties of Inorganic Glass under Ultrasonic Treatment," International Journal of Pharmaceutical Research, vol. 12, Supplementary Issue 2, pp. 1829-1832, 2020.

[46] M. O. Kaptakov, "Enhancement of Quality of Oil Products under Ultrasonic Treatment," International Journal of Pharmaceutical Research, vol. 12, Supplementary Issue 2, pp. 1851-1855, 2020.

[47]B. A. Garibyan, "Mechanical Properties of Electroconductive Ceramics," International Journal of Pharmaceutical Research, vol. 12, Supplementary Issue 2, pp. 1825-1828, 2020.

[48] M. O. Kaptakov, "Effect of Ultrasonic Treatment on Stability of $\mathrm{TiO}_{2}$ Aqueous Dispersions in Presence of Water-Soluble Polymers," International Journal of Pharmaceutical Research, vol. 12, Supplementary Issue 2, pp. 1821-1824, 2020.

[49] Yu. V. Ioni, "Synthesis of Metal Oxide Nanoparticles and Formation of Nanostructured Layers on Surfaces under Ultrasonic Vibrations," International Journal of Pharmaceutical Research, vol. 12, i. 4, pp. 3432-3435, 2020.

[50]N. A. Bulychev, E. L. Kuznetsova, "Ultrasonic Application of Nanostructured Coatings on Metals," Russian Engineering Research, 39 (9), pp. 809-812, 2019.

[51]N. A. Bulychev, V. V. Bodryshev, L. N. Rabinskiy, "Analysis of geometric characteristics of two-phase polymer-solvent systems during the separation of solutions according to the intensity of the image of micrographs," Periodico Tche Quimica, 16(32), pp. 551$559,2019$.

[52] N. A. Bulychev, A. V. Ivanov, "Effect of vibration on structure and properties of polymeric membranes," International Journal of Nanotechnology, vol. 16, nos. 6/7/8/9/10, pp. 334 - 343, 2019.

[53] N. A. Bulychev, A. V. Ivanov, "Nanostructure of OrganicInorganic Composite Materials Based on Polymer Hydrogels," International Journal of Nanotechnology, vol. 16, nos. 6/7/8/9/10, pp. $344-355,2019$.

[54] N. A. Bulychev, A. V. Ivanov, "Study of Nanostructure of Polymer Adsorption Layers on the Particles Surface of Titanium Dioxide," International Journal of Nanotechnology, vol. 16 , nos. 6/7/8/9/10, pp. $356-365$, 2019.

[55]N. A. Bulychev, L. N. Rabinskiy, "Ceramic Nanostructures Obtained by Acoustoplasma Technique," Nanoscience and Technology: An International Journal, 10 (3), pp. 279-286, 2019. 
[56] Yu. V. Ioni, A. Ethiraj, "Study of Microparticles Surface Modification by Electrokinetic Potential Measuring," International Journal of Pharmaceutical Research, vol. 12, i. 4, pp. 3436-3439, 2020.

[57] G. A. Kalugina, A. V. Ryapukhin, "Impact of the 2020 Pandemic on Russian Aviation," Russian Engineering Research, vol. 41. no. 7, pp. 627-630, 2021.

[58]R. N. Zaripov, I. M. Murakaev, A. V. Ryapukhin, "Development of the Organization's Key Performance Indicators System in Order to Improve the Effectiveness of Its Human Capital and Risk Management," TEM Journal, vol. 10, no. 1, pp. 298-302, 2021.

[59] A. A. Kalugin, G. A. Kalugina, A. V. Ryapukhin, "Informational Support for the Sale of Passenger Aircraft," Russian Engineering Research, vol. 41, no. 2, pp. 183-187, 2021.

[60] R. N. Zaripov, I. M. Murakaev, S. V. Novikov, A. V. Ryapukhin, "Corporate Structure for Innovative Enterprises," Russian Engineering Research, vol. 40, no. 2, pp. 137-139, 2020.

[61] A. Y. Burova, "Concept of multistage discrete fourier transform without performing multiplications" Journal of Physics: Conference Series, vol. 1889, no. 2, 022003, 2021.

[62] A. Burova, "Reducing the Error of Digital Algorithms for Deductive Signal Processing Based on Their Multi-Stage Discrete Fourier Transform by the Difference Digital Filters," 22th International Conference on Digital Signal Processing and its Applications, DSPA 2020, no. 9213275, 2020.

[63] A. Y. Burova, "Minimization of asymmetry of thrust of dual-flow turbojet engines of airliner in accordance with the results of system analysis of thrust parameters," Asia Life Sciences, no. 2, pp. 629-643, 2019.

[64] N. V. Britvin, E. O. Karpukhin, "Determining the linear network code parameters to minimize the destructive factors influence in telecommunications systems and networks," Journal of Physics: Conference Series, vol. 1889, no. 3, 032016, 2021.

[65] S. V. Grazion, M. V. Mukomela, M. N. Erofeev, V. V. Spiryagin, S. S. Amelin, "Experimental Estimation of the Waveguide Effect on the Acoustic Emission Signal Parameters in Monitoring Facilities with a Long Surface Radius of Curvature," Journal of Machinery Manufacture and Reliability, vol. 49, no. 11, pp. 971-979, 2020.

[66] M. I. Gordeeva, "Methods for forecasting and control of the phase composition and residual voltage in $\mathrm{Al}-\mathrm{Cu}-\mathrm{Li}$ alloys in friction mixing welding" Journal of Physics: Conference Series, vol. 1713, no. 1, 012017, 2020.

[67] Yu. V. Ioni, "Effect of Ultrasonic Treatment on Properties of Aqueous Dispersions of Inorganic and Organic Particles in Presence of Water-Soluble Polymers," International Journal of Pharmaceutical Research, vol. 12, i. 4, pp. 3440-3442, 2020.

[68] V. F. Formalev, S. A. Kolesnik, B. A. Garibyan, "Heat transfer with absorption in anisotropic thermal protection of high-temperature products," Herald of the Bauman
Moscow State Technical University, Series Natural Sciences, (5), pp. 35-49, 2019.

[69] S. A. Kolesnik, N. A. Bulychev, "Numerical analytic method for solving the inverse coefficient problem of heat conduction in anisotropic half-space," Journal of Physics: Conference Series, 1474(1), 012024, 2020.

[70] V. F. Formalev, N. A. Bulychev, S. A. Kolesnik, M. A. Kazaryan, "Thermal state of the package of cooled gasdynamic microlasers," Proceedings of SPIE - The International Society for Optical Engineering, 11322, article number 113221B, 2019.

[71] V. F. Formalev, S. A. Kolesnik, B. A. Garibyan, "Analytical solution of the problem of conjugate heat transfer between a gasdynamic boundary layer and anisotropic strip," Herald of the Bauman Moscow State Technical University, Series Natural Sciences, 5(92), pp. 44-59, 2020.

[72]Y. Sun, S. A. Kolesnik, E. L. Kuznetsova, "Mathematical modeling of coupled heat transfer on cooled gas turbine blades," INCAS Bulletin, 12(Special Issue), pp. 193-200, 2020.

[73] I. Kurchatov, N. Bulychev, S. Kolesnik, E. Muravev, "Application of the direct matrix analysis method for calculating the parameters of the luminescence spectra of the iron ion in zinc sulfide crystals," AIP Conference Proceedings, 2181, 020015, 2019.

[74] A. N. Astapov, I. P. Lifanov, L. N. Rabinskiy, "Perspective Heat-Resistant Coating for Protection of $\mathrm{Cf} / \mathrm{SiC}$ Composites in Air Plasma Hypersonic Flow,2 High Temperature, 57(5), pp. 744-752, 2019.

\section{Sources of Funding for Research Presented in a Scientific Article or Scientific Article Itself}

This study was funded by RFBR, project number 20-0800880 .

\section{Creative Commons Attribution License 4.0 (Attribution 4.0 International, CC BY 4.0)}

This article is published under the terms of the Creative Commons Attribution License 4.0

https://creativecommons.org/licenses/by/4.0/deed.en_US 